\title{
Suicide by self-inflicted stab wound to the heart: a rare case of suicide from Nepal
}

\author{
Jha $\mathbf{S}^{1}$, Parajuli SR ${ }^{2}$, Subedi ND ${ }^{3}$ \\ ${ }^{1}$ Associate Professor ${ }^{2} \mathrm{MD}$ Resident, Forensic Medicine and Toxicology, BP Koirala Instution of Health \\ Sciences, Dharan, Nepal, ${ }^{3}$ Lecturer, Forensic Medicine and Toxicology, College of Medical Sciences, \\ Bharatpur, Nepal
}

\begin{abstract}
Suicide, or the deliberate act of killing oneself, accounts for a substantial number of unnatural deaths each year in many countries. Though death by self-stabbing is quite uncommon, the left part of the chest represents one of the elected sites of self-inflicted wounds because of the knowledge of the situation of the heart and that the injuries to the heart are severe. We present a case of suicidal stab to the left thoracic region involving the heart.
\end{abstract}

\section{Keywords: Autopsy, death, suicide, stab injury}

\section{INTRODUCTION}

Suicide, or the deliberate act of killing oneself, accounts for a substantial number of unnatural deaths each year in many countries. Methods that are used in cases of suicide vary among populations and communities, as well as over time. ${ }^{1}$ According to the WHO, every year, almost one million people die from suicide and 20 times more people attempt suicide; a global mortality rate of 16 per 100,000 , or one death every 40 seconds and one attempt every 3 seconds, on average. ${ }^{2}$ Self-stabbing is an uncommon method of suicide. The left part of the chest (where popular knowledge believes the heart to be) represents one of the elected sites of self-inflicted wounds. ${ }^{3}$

\section{CASE REPORT}

Correspondence: Shivendra Jha

Email: drshivendrajha@gmail.com
A 55 year old man allegedly stabbed his left chest at 7:00 pm by sharp cutting weapon. He had argument with his daughter and suddenly stabbed himself. Previous attempts were not present. No known psychiatric conditions were reported for which medication was done. His wife had died 3 months back due to diseased condition and he was under stress. He used to consume alcohol on daily basis since last 30 to 35 years and on this day too. He was an ex-army from Nepal and was currently working as a security guard in one of the school for last few years as stated by his son. Shortly after the incident, he was brought to the BPKIHS hospital in eastern Nepal and was declared dead on arrival.

No crime scene investigation was done as he was immediately brought to hospital and as per inquest done by police; injuries were present in left chest. The postmortem examination was done after 16 hours of his death and revealed rigor mortis all over body 
Jha S. et al, Suicide by self-inflicted stab wound to the heart..

and livor mortis in back except contact pallor. There was a stab wound of $3 \mathrm{~cm} \times 1.5 \mathrm{~cm}$ with superior sharp end and inferior blunt end on left chest region, placed slightly obliquely, $2.5 \mathrm{~cm}$ from mid sternal line in $3^{\text {rd }}$ intercostal space, $6 \mathrm{~cm}$ from left nipple. Three tentative marks (hesitation cuts) were seen below this injury. After a median sternotomy, a depth penetration of the stab channel revealed the cut of the skin and subcutaneous layers and, going through the left $3^{\text {rd }}$ intercostals space with $4^{\text {th }}$ rib fracture on upper margin, hematoma with about $1500 \mathrm{ml}$ of blood was seen in the thoracic cavity. Heart was examined and a vertical $1 \mathrm{~cm}$ penetrating injury on right ventricle was revealed. All the chambers of the heart were empty.

Death occurred within an hour, from the time of self-injury to arrival at hospital. The cause of death was determined to be due to exsanguination from penetrating injury to the heart.

\section{DISCUSSION}

Suicide is a frequent cause of death all over the world. Death by self-stabbing is quite uncommon in Western countries. Mostly young men and persons with a psychiatric history choose this manner of suicide. ${ }^{3}$ Hemorrhage from penetrating injuries to chest may remain concealed with little external evidence of bleeding and it is not unusual to find several liters blood with in the chest cavity at post-mortem examination. ${ }^{4}$ Suicidal wounds of the chest are usually on the left side, and directed downwards and inwards, unless the person happens to be left-handed. ${ }^{5}$

In the case described, the 55 year old man had no eventful psychiatric history but was a chronic alcoholic. The presence of several self-inflicted stabs and hesitation marks and the absence of clothing are the classic criteria required for a self-inflicted suicide. ${ }^{3}$ In this case, there was a single incision penetrating the chest on the left side with three hesitation marks beneath it.

The physiologic status of the patient at presentation, mechanism of injury, and presence of a tamponade are significant prognostic factors in penetrating cardiac injuries. Penetrating cardiac wounds represent an ongoing clinical challenge to trauma surgeons. ${ }^{6}$ The outcome of patients with penetrating heart injuries depends to a great extent on aggressive primary care and fast transport to the closest appropriate trauma center. There, after confirming the diagnosis, the injured victim has to be transferred without any delay to the operating room where the penetrating injury can be dealt with. ${ }^{7}$

Lack of cardiac trauma centre and cardiac surgeons in this institute and whole eastern Nepal, the case we described would not have survived even if it has reached the hospital. This is the scenario in almost all areas of Nepal excluding the capital, Kathmandu. The most important factor for survival in cardiac trauma would be to stabilize the hemodynamic state with the urgent treatment just after arrival and to perform the surgical repair immediately. ${ }^{8} \mathrm{~A}$ large variation in survival rates, ranging from 19 to $65 \%$ is reported. ${ }^{6}$ Viewing all, we can confirm the unusual case of a selfstabbing suicide of a man penetrating his own heart. 
Jha S. et al, Suicide by self-inflicted stab wound to the heart

\section{REFERENCES}

1. Austin $A E$, Heath $K$, Gilbert JD, et al. Head impalement - An unusual form of suicide. Journal of Forensic and Legal Medicine 2012;19(5):264-6.

2. Radhakrishnan R, Andrade C. Suicide: An Indian perspective. Indian J Psychiatry 2012;54(4):304-19.

3. Pentone $A$, Innamorato L, Introna $F$. Dying Transfixing His Own Heart A Rare Case of Suicide by Stabbing. Am J Forensic Med Pathol 2013;34:318-20.

4. Payne-James J, Jones R, Karch SB, et al. Simpson's Forensic Medicine. 13 ed2011. p. 108.

5. Modi JP. A Textbook of Medical Jurisprudence and Toxicology. In: Justice K Kannnan DKM, editor. $24^{\text {th }}$ edi: Lexis Nexis. p. 569.

6. Tyburski JG, Astra L, Wilson RF, et al. Factors Affecting Prognosis with Penetrating Wounds of the Heart. Journal of Trauma-Injury Infection \& Critical care. April 2000;48(4):587-91.

7. Stahl JP, Stertmann WA, Zimmermann T, et al. Penetrating knife injury of the heart. Emergency management and definitive treatment: case report and review of the literature. Unfallchirurg 2003 Feb;106(2):176-81.

8. Nakano H, Chikazawa G, Tabuchi T.

Penetrating right ventricular trauma by stab injury; report of a case. Kyobu

Geka. 2005 Sep;58(10):915-9. 